Technical Note

\title{
A novel objective evaluation method for trunk function
}

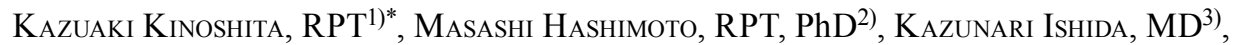
Yuki Yoneda, RPT ${ }^{4)}$, Yuta Naka, RPT ${ }^{4)}$, Hideyuki Kitanishi, RPT ${ }^{4}$, Hirotaka Oyagi, RPT ${ }^{4}$, Yuichi Hoshino, MD ${ }^{3)}$, NaO Shibanuma, MD $^{3)}$

1) Department of Physical Therapy, Faculty of Rehabilitation, Shijonawate Gakuen University: 5-11-10 Hojo, Daito, Osaka 574-0011, Japan

2) Faculty of Rehabilitation, Osaka Kawasaki Rehabilitation University, Japan

3) Department of Orthopaedic Surgery, Kobe Kaisei Hospital, Japan

4) Department of Rehabilitation Center, Kobe Kaisei Hospital, Japan

\begin{abstract}
Purpose] To investigate whether an objective evaluation method for trunk function, namely the "trunk righting test", is reproducible and reliable by testing on different observers (from experienced to beginners) and by confirming the test-retest reliability. [Subjects] Five healthy subjects were evaluated in this correlation study. [Methods] A handheld dynamometer was used in the assessments. The motor task was a trunk righting motion by moving the part with the sensor pad $10 \mathrm{~cm}$ outward from the original position. During measurement, the posture was held at maximum effort for $5 \mathrm{~s}$. Measurement was repeated three times. Interexaminer reproducibility was examined in two physical therapists with 1 year experience and one physical therapist with 7 years of experience. The measured values were evaluated for reliability by using intraclass correlation coefficients (ICC 1.1) and interclass correlation coefficients (ICC 2.1). [Results] The test-retest reliability ICC 1.1 and ICC 2.1 were all high. The ICC 1.1 was $>0.90$. The ICC 2.1 was 0.93 . [Conclusion] We developed the trunk righting test as a novel objective evaluation method for trunk function. As the study included inexperienced therapists, the results suggest that the trunk righting test could be used in the clinic, independent of the experience of the therapists.

Key words: Trunk function, Reliability, Handheld dynamometer
\end{abstract}

(This article was submitted Dec. 1, 2014, and was accepted Jan. 11, 2015)

\section{INTRODUCTION}

The trunk consists of many different muscles that stabilize the spine, pelvis, and shoulder, and provides a foundation for the movement of the extremities. The muscles of the trunk help control movements, transfer energy, shift body weight, and distribute the stresses of weight bearing ${ }^{1-3)}$. Many different muscles comprise the trunk. These muscles are classified into local and global muscles depending on their anatomical orientation and function ${ }^{4}$. Local muscles, which have more direct or indirect attachments to the lumbar vertebrae, are associated with the segmental stability of the lumbar spine ${ }^{4)}$. Global muscles, those that attach to the hips and pelvis, are related to torque production and to the transfer of load between the thoracic cage and the pelvis ${ }^{4}$. The interdependency of the osseoligamentous structures, trunk muscles, and neural control of the muscles is needed for optimal trunk stability ${ }^{5)}$. Particularly, coordination and co-contraction of

*Corresponding author. Kazuaki Kinoshita (E-mail: k-kinoshita@reha.shijonawate-gakuen.ac.jp)

C2015 The Society of Physical Therapy Science. Published by IPEC Inc. This is an open-access article distributed under the terms of the Creative Commons Attribution Non-Commercial No Derivatives (by-ncnd) License $<$ http://creativecommons.org/licenses/by-nc-nd/3.0/>. these local and global muscles are important ${ }^{6}$ ). Thus, "trunk stability" is considered the ability to control the position and motion of the trunk during dynamic loading and movement conditions ${ }^{7}$.

Trunk stability is integral to performing the activities of daily living ${ }^{8)}$. For example, lower levels of trunk muscle attenuation have been associated with reduced functional capacity in healthy older adults ${ }^{9}$. Furthermore, cross-sectional studies reported small-to-medium correlations between trunk muscle strength and balance, functional performance, and falls in older adults ${ }^{10)}$.

Therefore, trunk function training has been the focus of research in recent years ${ }^{11-13)}$. Mori et al. reported that ball exercise was effective in comprehensively improving muscle strength, endurance, and flexibility, as well as strengthening body reflexes, sense of balance, and proprioception in subjects with low back pain ${ }^{14)}$. Stanton et al. ${ }^{15)}$ also reported that the Swiss ball exercise is an effective stability exercise for trunk core muscles. However, few papers thus far have reported on objective evaluation methods for trunk function ${ }^{16)}$. For example, in a previous study, subjects were instructed to hold the postures indicated in "The FIFA $11+$ ", and the endurance time was recorded to evaluate the trunk function ${ }^{16)}$. If the objective and reproduction of simple methods for trunk function are established, it is possible to evaluate the core function more easily as important factors 
of physical performance.

Recently, we have started to use a novel test to evaluate the trunk function in patients with musculoskeletal disease in the lower extremities. The test involved a body righting movement while sitting on the bed, thus named the "trunk righting test" (TRT). The aim of this study is to investigate whether TRT is a reproducible and reliable test for the observers, independent of their experience.

\section{SUBJECTS AND METHODS}

Five healthy volunteer subjects (three men and two women; age, $33.2 \pm 9.7$ years; height, $164.6 \pm 13.3 \mathrm{~cm}$; weight, $56.6 \pm 13.2 \mathrm{~kg}$ ) were evaluated in this study (Table 1). The purpose of the study was explained, and informed consent was obtained from all subjects. The TRT was performed by using a handheld dynamometer ( $\mu$ Tas F-1; ANIMA Co., Tokyo, Japan). The measurement range of this dynamometer is $0.1-999.9 \mathrm{~N}$, with a recording interval of $0.1 \mathrm{~N}$. The handheld dynamometer can be used to quantify maximal strength and may offer several advantages, including ease of transport, time efficiency, and low cost ${ }^{17}$. The subjects were seated on a box with their feet above the ground. Both lower extremities were fixed with a band at the level of the thighs to suppress the compensation operation. The observer confirmed that the line connecting the bilateral acromion is parallel to the floor. Moreover, the sensor pad was fixed on the inner part of the acromioclavicular joint by adjusting the length of the belt restraint strap to be perpendicular to the bearing surface (Fig. 1). Then, the subjects were asked to move their shoulder with the sensor, $10 \mathrm{~cm}$ outward from the original position (Fig. 2). At that time, the subjects were confirmed to maintain the mirror position, keeping the line connecting the bilateral acromion parallel, and the fixing belt perpendicular to the floor. Furthermore, the observers placed

Table 1. Data of subject specific factors

\begin{tabular}{lc}
\hline & Value $($ mean \pm SD) \\
\hline Males / females & $3 / 2$ \\
Age (yrs) & $33.2 \pm 9.7$ \\
Height $(\mathrm{cm})$ & $164.6 \pm 13.3$ \\
Weight $(\mathrm{kg})$ & $56.6 \pm 13.2$ \\
\hline
\end{tabular}

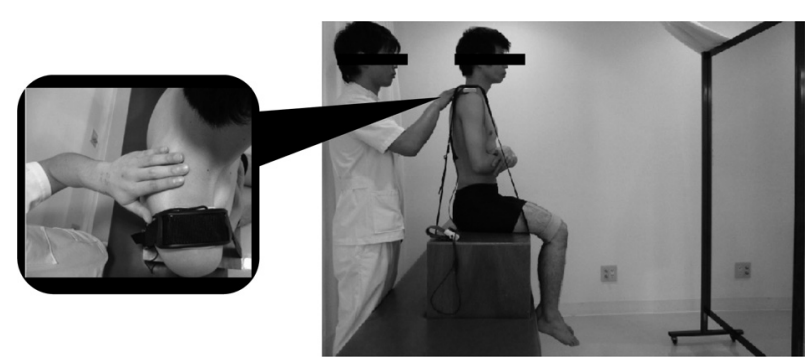

Fig. 1. Start position of the trunk righting test The examiner palpates the line in the upper portion of the trapezius muscle. The examiner prevents the compensation. The subject confirms the position of the plate while looking at the mirror. their palm above the trapezius muscle of the subjects to prevent the elevation of the shoulder girdle. The subjects applied maximum power to the belt for $5 \mathrm{~s}$, and the highest values were used in this study. The measurements were repeated three times per day with at least $>30 \mathrm{~s}$ interval to negate the influence of fatigue. The measurements were repeated after $>2$ days interval; thus, a total of six measurements were performed. The evaluation was performed by one of the authors who was blind to the examination. To examine the interexaminer reproducibility, a total of three observers participated in this study. Two of the three observers are resident physical therapists with 1 year experience (examiners A and B); the other observer is a senior therapist (examiner C). Physical measurements were evaluated by using intraclass correlation coefficients (ICC 1.1) and interclass correlation coefficients (ICC 2.1). The ICC 1.1 and ICC 2.1 reliability was examined for each variable. Reliability was calculated separately for the right and left measured values. ICC calculations were performed by using SPSS (version 21). The range of ICC values was described by using the classification of Fleiss, and ICC $>0.75$ was considered excellent ${ }^{18)}$. This study reported the contents of the research in Kobe Kaisei hospital ethical committee. And we had the consent of that to carry out research under the guidance of the ethical committee. All of the subjects understood the purpose of this study and provided written informed consent before participation according to the ethical standards of the Declaration of Helsinki.

\section{RESULTS}

The test-retest reliability ICC 1.1 and ICC 2.1 were all high (Table 2). The ICC 1.1 values were as follows: examiner A, 0.93; examiner B, 0.96; and examiner C, 0.90. The a.

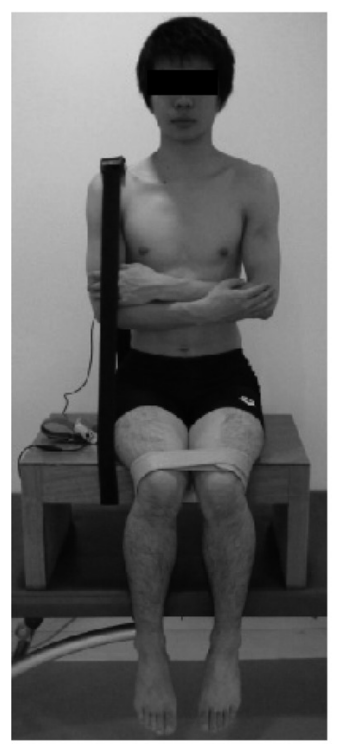

b.

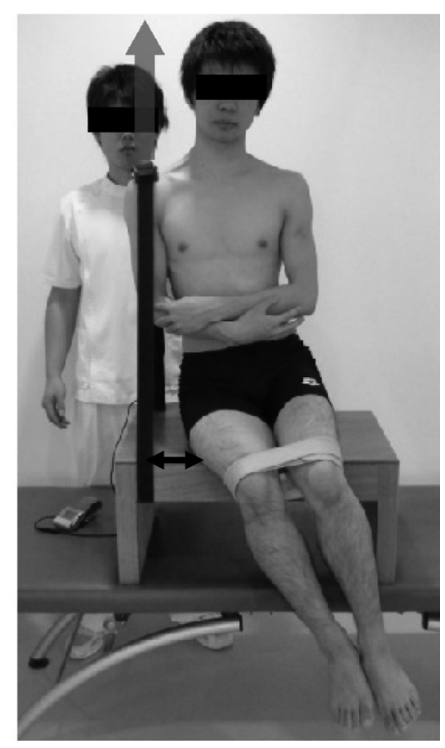

Fig. 2. The length of the belt is decided according to the start position. The sensor of the handheld dynamometer is placed on the inner part of the acromioclavicular joint (a). The position of the belt is moved by $10 \mathrm{~cm}$ toward the side (b). 
ICC 2.1 was 0.93 . I represents the results of the five subjects (Table 3). This is the average of the three subjects.

\section{DISCUSSION}

The most important aim of this study is to develop the TRT as a novel objective evaluation method for trunk function. The intraexaminer intraclass correlation coefficient showed that the reproducibility was higher than the standard of 0.90 , confirming that the test could be performed with excellent reproducibility within the same examiners. Furthermore, the interclass correlation coefficient was also as high at 0.93 , revealing that the interobserver reproducibility is also high. There was no statistically significant difference between the therapists with different levels of experience. The results suggest that the test is simple and reproducible even for inexperienced therapists, and that the TRT could be used in the clinic, independent of the experience of the therapists.

This study has some limitations. First, the study was performed in healthy subjects. It may be difficult to use for subjects with clumsy or impervious to the explanation. Second, quantitative evaluation of trunk function was not performed in this study. However, no objective method to quantify the trunk function has been established, and it might be impossible to correctly evaluate the TRT. Third, the consistency between different subjects is unknown to this study. Thus, further investigation is needed to determine whether the TRT will be a useful evaluation method for comparing trunk function in different subjects. Finally, this paper does not include clinical information that supports the importance of this test, although the TRT has already started to be used clinically at

Table 2. Test-retest reliability data for the trunk righting test in the three examiners

\begin{tabular}{rr}
\hline Test-retest reliability ICC(1.1) A & 0.93 \\
B & 0.96 \\
C & 0.90 \\
Test-retest reliability ICC(2.1) & 0.93 \\
\hline
\end{tabular}

our institution. Further studies are needed to confirm the importance of this test in clinical use, including a comparison within the same subjects at different time points.

In the TRT, the power toward the floor from the pelvis

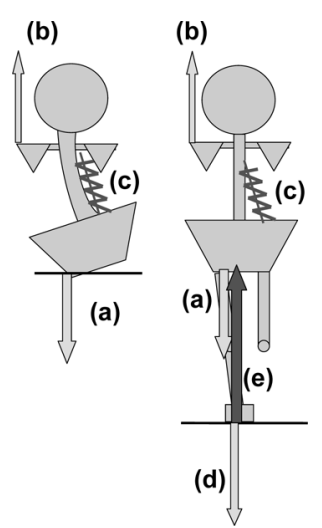

Fig. 3. In the TRT, the power toward the floor from the pelvis was transmitted to the belt and measured at the upper shoulder girdle of the same side. Simultaneously, asymmetric trunk muscle activity was required to fix the trunk; thus, the power measured in this test was considered to come from trunk. With the subjects in the standing position, the supporting force from trunk muscle was transmitted to the lower extremities and combined with the force from the lower extremities. The combined force would be the power against the floor force, and would be the mechanical base for body movements and posture stability against gravity.

(a) In the trunk righting test, the floor is pressed with the support of the pelvic region.

(b) The power is reflected in the pushing force to the upper shoulder girdle of the same side. The trunk righting test is performed to measure the trunk force.

(c) To fix the trunk, right and left asymmetry in muscle activity is required.

(d) With the subject in the standing position, the supporting force is transmitted to the lower limbs from the trunk.

(e) The floor reaction force from pushing the floor becomes the power source for antigravity activities; it will be mechanical foundation of body movements and posture stability against gravity.

Table 3. Measurement data for the trunk righting test in the five subjects

\begin{tabular}{rcccccc}
\hline & \multicolumn{3}{c}{ Trial 1 } & \multicolumn{3}{c}{ Trial 2 } \\
\cline { 2 - 6 } & First time & Second time & Third time & First time & Second time & Third time \\
\hline Subject A R & $146.3 \pm 54.5$ & $120.0 \pm 22.7$ & $131.3 \pm 9.5$ & $128.0 \pm 11.4$ & $120.0 \pm 28.0$ & $127.3 \pm 11.1$ \\
L & $77.7 \pm 19.6$ & $82.3 \pm 7.6$ & $78.3 \pm 7.2$ & $67.3 \pm 5.0$ & $67.3 \pm 10.7$ & $71.0 \pm 14.1$ \\
Subject B R & $156.7 \pm 9.8$ & $151.3 \pm 8.3$ & $148.3 \pm 13.6$ & $136.0 \pm 34.8$ & $125.3 \pm 27.6$ & $143.7 \pm 9.1$ \\
L & $168.7 \pm 17.6$ & $176.0 \pm 19.0$ & $168.3 \pm 7.5$ & $172.7 \pm 14.0$ & $195.3 \pm 5.1$ & $176.3 \pm 2.9$ \\
Subject C R & $214.0 \pm 7.9$ & $222.7 \pm 9.7$ & $213.0 \pm 5.0$ & $223.7 \pm 2.5$ & $212.0 \pm 4.0$ & $211.0 \pm 2.6$ \\
L & $213.3 \pm 11.0$ & $218.0 \pm 16.7$ & $227.0 \pm 20.0$ & $232.7 \pm 1.2$ & $234.0 \pm 8.0$ & $229.3 \pm 6.1$ \\
Subject D R & $95.3 \pm 7.2$ & $94.0 \pm 3.5$ & $96.7 \pm 15.0$ & $106.0 \pm 9.6$ & $91.3 \pm 2.5$ & $96.3 \pm 4.0$ \\
L & $91.0 \pm 8.2$ & $86.0 \pm 10.6$ & $86.0 \pm 10.6$ & $84.3 \pm 12.1$ & $86.7 \pm 7.5$ & $87.0 \pm 9.6$ \\
Subject E R & $150.7 \pm 16.3$ & $149.0 \pm 9.5$ & $150.0 \pm 11.3$ & $145.7 \pm 19.7$ & $144.3 \pm 16.2$ & $140.7 \pm 10.7$ \\
L & $108.7 \pm 9.0$ & $108.7 \pm 5.7$ & $109.0 \pm 4.4$ & $110.7 \pm 17.0$ & $109.0 \pm 8.7$ & $103.0 \pm 17.7$ \\
\hline
\end{tabular}

Mean \pm SD 
was transmitted to the belt and measured at the upper shoulder girdle of the same side. Simultaneously, asymmetric trunk muscle activity was required to fix the trunk; thus, the power measured in this test was considered to come from trunk. With the subjects in the standing position, the supporting force from trunk muscle was transmitted to the lower extremities and combined with the force from the lower extremities. The combined force would be the power against the floor force, and would be the mechanical base for body movements and posture stability against gravity (Fig. 3 ). Thus, the force from the trunk, transmitted to the lower extremities, is considered to be essential for such movements and for stability. TRT is considered to measure this trunk force; thus, it is believed that the assessment of trunk function by using TRT is important.

\section{REFERENCES}

1) Hedrick A: Training the trunk for improved athletic performance. Strength Condit J, 2000, 22: 50-61. [CrossRef]

2) Jamison ST, McNeilan RJ, Young GS, et al.: Randomized controlled tria of the effects of a trunk stabilization program on trunk control and knee loading. Med Sci Sports Exerc, 2012, 44: 1924-1934. [Medline] [CrossRef]

3) Guskiewicz K: Rehabilitation Techniques for sports medicine and athletic training Prentice. W E 5th ed. New York: McGraw Hill, 2011. Regaining postural stability and balance; pp 145-170.

4) Bergmark A: Stability of the lumbar spine. A study in mechanical engineering. Acta Orthop Scand Suppl, 1989, 230: 1-54. [Medline] [CrossRef]

5) Panjabi MM: The stabilizing system of the spine. Part I. Function, dysfunction, adaptation, and enhancement. J Spinal Disord, 1992, 5: 383-389, discussion 397. [Medline] [CrossRef]

6) Akuthota V, Ferreiro A, Moore T, et al.: Core stability exercise principles. Curr Sports Med Rep, 2008, 7: 39-44. [Medline] [CrossRef]
7) Mills JD, Taunton JE, Mills WA: The effect of a 10-week training regimen on lumbo-pelvic stability and athletic performance in female athletes: A randomized-controlled trial. Phys Ther Sport, 2005, 6: 60-66. [CrossRef]

8) Ryan AS, Harduarsingh-Permaul AS: Effects of weight loss and exercise on trunk muscle composition in older women. Clin Interv Aging, 2014, 9: 395-402. [Medline] [CrossRef]

9) Hicks GE, Simonsick EM, Harris TB, et al.: Cross-sectional association between trunk muscle composition, back pain, and physical function in the health, aging and body composition study. J Gerontol A Biol Sci Med Sci, 2005, 60: 882-887. [Medline] [CrossRef]

10) Granacher $U$, Gollhofer A, Hortobágyi $T$, et al.: The importance of trunk muscle strength for balance, functional performance, and fall prevention in seniors: a systematic review. Sports Med, 2013, 43: 627-641. [Medline] [CrossRef]

11) Fredericson $M$, Moore $T$ : Muscular balance, core stability, and injury prevention for middle- and long-distance runners. Phys Med Rehabil Clin N Am, 2005, 16: 669-689. [Medline] [CrossRef]

12) Granata KP, Slota GP, Wilson SE: Influence of fatigue in neuromuscular control of spinal stability. Hum Factors, 2004, 46: 81-91. [Medline] [CrossRef]

13) Sato K, Mokha M: Does core strength training influence running kinetics, lower-extremity stability, and 5000-M performance in runners? J Strength Cond Res, 2009, 23: 133-140. [Medline] [CrossRef]

14) Mori A: Electromyographic activity of selected trunk muscles during stabilization exercises using a gym ball. Electromyogr Clin Neurophysiol, 2004, 44: 57-64. [Medline]

15) Stanton R, Reaburn PR, Humphries B: The effect of short-term Swiss ball training on core stability and running economy. J Strength Cond Res, 2004, 18: 522-528. [Medline]

16) Nakazawa R, Endo Y, Sakamoto M: The relationship between trunk function and injury among junior high school soccer players. J Phys Ther Sci, 2013, 25: 775-777. [Medline] [CrossRef]

17) Suzuki M, Omori $Y$, Sugimura $S$, et al.: Predicting recovery of bilateral upper extremity muscle strength after stroke. J Rehabil Med, 2011, 43: 935-943. [Medline]

18) Munro A, Herrington L, Carolan M: Reliability of 2-dimensional video assessment of frontal-plane dynamic knee valgus during common athletic screening tasks. J Sport Rehabil, 2012, 21: 7-11. [Medline] 